\title{
O ESTUDO DA MEMÓRIA SOCIAL NA GRADUAÇÃO EM CIÊNCIA DA INFORMAÇÃO: UM RELATO DE EXPERIÊNCIA
}

\begin{abstract}
Resumo: O presente trabalho apresenta um relato de experiência docente junto à disciplina Informação e Memória Social, do Departamento de Ciência da Informação da Universidade Federal do Rio Grande do Sul. A disciplina é ofertada como matéria obrigatória no currículo do curso de graduação em Museologia e como eletiva nos currículos dos cursos de Arquivologia, Biblioteconomia, Jornalismo, Publicidade e Propaganda, Relações Públicas e História da Arte. Com base nessa experiência didática no decorrer do semestre 2017/2, descrevem-se os principais autores e conceitos estudados, a sistemática das aulas e a metodologia de avaliação aplicada aos discentes. O conteúdo programático inclui referências sobre memória, esquecimento, memória neurofisiológica, falsas memórias, memória coletiva, memória social, memória e história, direito à memória, memória institucional, memória virtual, nostalgia e noções sobre a dimensão política da memória e o patrimônio, sempre tendo em vista o papel das práticas informacionais nos processos mnemônicos. A partir dessa experiência, são apresentadas formas de se trabalhar os autores e as teorias do campo de estudo em Memória Social na área da Ciência da Informação, de modo a evidenciar as suas principais contribuições para a área, sempre buscando uma abordagem pedagógica atualizada aos nativos da era digital.
\end{abstract}

Palavras-chave: Memória Social. Ciência da Informação. Experiência Didática. Educação. Era Digital.
Luis Fernando Herbert Massoni

Doutorando e mestre em Comunicação e Informação (PPGCOM/UFRGS)

Universidade Federal do Rio Grande do Sul

luisfernandomassoni@gmail.com

Priscila Chagas Oliveira

Mestra em Memória Social e Patrimônio Cultural (PPGMP/UFPEL)

Universidade Federal de Pelotas priscila.museo@gmail.com

Andréa Reis da Silveira Doutoranda em História (PPGH/UDESC) e mestra em Patrimônio Cultural (PPGPPC/UFSM)

Universidade do Estado de Santa Catarina andrears1965@gmail.com

Marcia Heloisa Tavares Figueredo Lima Mestra e Doutora em Ciência da Informação (PPGCI/IBICT-UFRJ) Professora adjunta do Departamento de Ciência da Informação (DCI) da Universidade Federal do Rio Grande do Sul UFRGS marciahelolima@gmail.com

\section{THE SOCIAL MEMORY STUDY IN INFORMATION SCIENCE GRADUATION: A REPORT} ON A EXPERIENCE

\begin{abstract}
This presentation is a report on a teaching experience in the undergraduate course of Information and Social Memory in the Department of Information Sciences at the Federal University of Rio Grande do Sul (UFRGS). This class is mandatory for undergraduates in Museum Sciences and optional class for undergraduates in Archive Studies, Library Science, Journalism, Publicity and Advertising, Public Relations and Art History. Based on this teaching experience which took place in the second semester of 2017, the main authors and concepts studied are described, as well as the class organization and the evaluation criteria used with the students. The course content includes references on memory, forgetfulness, neurophysical memory, fake memories, collective memory, social memory, history and memory, right to memory, institutional memory, virtual memory, nostalgia and notions on the political dimension of memory and patrimony, always keeping in mind the role of informational practices in mnemonic processes. Through this teaching experience, ways to present the authors and theories of the social memory field in relation to information sciences are presented, in order to highlight social memory's main contributions to the field, always looking for an updated pedagogical approach to teach the digital natives.
\end{abstract}

Keywords: Social Memory. Information Sciences. Teaching Experience. Education. Digital Era. 


\section{INTRODUÇÃO}

Interdisciplinar por natureza, a Ciência da Informação (CI) está preocupada com o estudo e a análise crítica dos mais variados fenômenos informacionais de nossa sociedade, apropriando-se de diversos conceitos e teorias de outras ciências, especialmente as advindas das grandes áreas de Ciências Humanas e Ciências Sociais. Conceitos como gestão, Tecnologias de Informação e Comunicação (TIC), cultura, cidadania, educação, mediação e patrimônio, dentre outros, lhe atribuem complexidade e parecem cada vez mais necessários para a reflexão proposta por esse campo.

A CI vem sendo pensada a partir de suas articulações com as áreas da Arquivologia, da Biblioteconomia e da Museologia, sendo esse diálogo explicitado e, por vezes problematizado, quando os cursos de graduação dessas três áreas compartilham de um único departamento. A fim de que esse diálogo se efetive e ainda possa contribuir para o desenvolvimento do campo, faz-se necessária a construção de currículos que compartilhem disciplinas em comum - principalmente as de caráter introdutório e as que fundamentam teoricamente essas áreas. Um dos conceitos principais de que se serve a CI e que perpassa necessariamente essas três áreas do conhecimento é o de memória social, uma vez que se trata do campo de estudo transdisciplinar das propriedades e dos fenômenos vivenciados por indivíduos e grupos, que são vistos a partir do presente em direção ao passado ou ao futuro (DODEBEI, 2011).

Assim, apresentamos um relato das experiências de ensino e aprendizagem durante o semestre 2017/2 das três turmas ${ }^{1}$ da disciplina Informação e Memória Social, que é ofertada pelo Departamento de Ciências da Informação (DCI) da Universidade Federal do Rio Grande do Sul. Para tanto, tecemos uma articulação teórica entre os conceitos abordados ao longo da disciplina, explicando de que modo esses conceitos foram trabalhados e como o encadeamento entre eles foi realizado. Após, são apresentados os objetivos, a metodologia, o referencial teórico e as formas de avaliação da disciplina. Por fim, refletimos sobre os principais desafios e oportunidades que se apresentam nessa reflexão sobre o conceito de memória nos cursos de

\footnotetext{
${ }^{1}$ No semestre 2017/2, a disciplina BIB03095 - Informação e Memória Social foi ofertada em três turmas - A, B e C -, cada uma com um professor diferente. Todas obedecendo a um mesmo plano de ensino, com pequenas alterações na forma de distribuir o conteúdo ao longo do semestre, de acordo com cada contexto (questões como dias não letivos ou reuniões tornaram necessária a readequação de alguns conteúdos ao longo do semestre em algumas turmas, noutras não).
} 
graduação em CI, ainda mais compreendendo a importância da aplicação e reflexão da utilização de processos criativos para educação na era digital.

\section{INFORMAÇÃO E MEMÓRIA SOCIAL: ARTICULAÇÕES TEÓRICAS}

A disciplina Informação e Memória Social conta com um quadro teórico interdisciplinar, relacionando e encadeando os conceitos de modo a problematizar diversas formas de manifestação da memória (englobando a lembrança e o esquecimento), da individual à coletiva.

O Quadro 1 apresenta os principais autores e conceitos discutidos ao longo do semestre. Na experiência relatada neste estudo, foi indicada, para cada aula, a leitura obrigatória de um texto - em algumas aulas, foram indicados textos complementares. Partiu-se de textos de mais fácil compreensão e/ou clássicos dos estudos em memória social, culminando em discussões mais complexas e contemporâneas da área, incluindo relatos de pesquisa em memória social, quando palestrantes foram chamados para expor suas pesquisas na área.

Quadro 1 - Disciplina Informação e Memória Social: principais autores e conceitos

\begin{tabular}{|l|l|}
\hline \multicolumn{1}{|c|}{ Autores (as) } & \multicolumn{1}{|c|}{ Principais conceitos } \\
\hline IZQUIERDO, Ivan (2004). & Memória Neurofisiológica. \\
\hline STEIN, Lilian; PERGHER, Giovanni (2001). & Falsas Memórias. \\
\hline $\begin{array}{l}\text { HALBWACHS, Maurice (2013). } \\
\text { CANDAU, Joel (2005). }\end{array}$ & $\begin{array}{l}\text { Memória Coletiva. } \\
\text { Metamemória Coletiva. }\end{array}$ \\
\hline GONDAR, Jô (2016). & Memória Social. \\
\hline NORA, Pierre (1993). & Lugares de Memória. \\
\hline ASSMANN, Aleida (2011). & Espaços de Recordação \\
\hline BOSI, Ecléa (1994). & Espços de Memória. \\
\hline POLLAK, Michael (1989). & $\begin{array}{l}\text { Memória e Esquecimento. } \\
\text { Memória e Identidade Social. }\end{array}$ \\
\hline LE GOFF, Jacques (2003). & Documento. Monumento. \\
\hline $\begin{array}{l}\text { THOMPSON, Paul (2002). } \\
\text { GUARINELLO, Norberto Luiz (1998). } \\
\text { AMADO, Janaína; FERREIRA, Marieta M. (2006). }\end{array}$ & História Oral. \\
\hline BENJAMIN, Walter (1985). & Narrativa. Narração. Narrador. \\
\hline $\begin{array}{l}\text { CUNHA, Magda (2011). } \\
\text { CASALEGNO, Federico (2006). }\end{array}$ & $\begin{array}{l}\text { Memória Virtual. } \\
\text { Memória Digital. }\end{array}$ \\
\hline
\end{tabular}




\begin{tabular}{|l|l|}
\hline DODEBEI, Vera (2006). & Memória em Rede. \\
LAZZARIN, Fabiana; NETTO, Carlos Xavier; SOUZA, & Memória no Ciberespaço. \\
Marckson (2015). & Patrimônio Digital. \\
MANGAN, Patrícia (2010). & \\
SANTAELLA, Lúcia (2016). & \\
\hline BORGES, Jorge Luis (1969). & Excesso de Memória. \\
\hline CHAGAS, Mário (2009). & Memória e Poder \\
\hline
\end{tabular}

Fonte: autoria nossa, 2018.

Professor aposentado da UFRGS, Ivan Izquierdo é pioneiro no estudo da neurobiologia da memória e do aprendizado, estando atualmente à frente do Centro de Memória da Pontifícia Universidade Católica do Rio Grande do Sul (PUCRS). Seus estudos sobre a memória concentram-se nos aspectos biológicos e fisiológicos inerentes ao processamento das informações no cérebro, sendo este o ponto de partida teórica da disciplina. O texto abordado (2004) é de fácil compreensão, aspecto fundamental, tendo em vista a etapa em que os alunos se encontram, a complexidade do assunto e o fato de que, na disciplina, não se pretende formar especialistas nos mecanismos biológicos da formação da memória.

Ademais, o texto de Izquierdo foi escolhido por destacar o papel da informação desde o conceito mais básico: "Memória é a aquisição, conservação e evocação de informações." (IZQUIERDO, 2004, p.15). Dentre outros conteúdos, o autor afirma que não há memória sem processo de seleção (esquecimento) e, assim, aborda a diferença entre a memória humana e as memórias de outros animais (faz referência à metáfora da memória das máquinas), explica que a memória é resultado da experiência pessoal e, de forma didática, desvenda a fisiologia do cérebro e dos neurônios, bem como suas funções, etc.

Destaca-se, de seus estudos, a classificação a respeito dos tipos de memória, que Izquierdo (2004) distingue com relação à sua duração (memória imediata, de curta duração e de longa duração) e à sua função (memória de trabalho, declarativa e procedural): a memória imediata dura segundos, é operacional e não deixa rastros; a memória de curta duração dura poucas horas e não causa alterações estruturais nos neurônios; a memória de longa duração pode durar anos e perpassa várias regiões do cérebro; a memória de trabalho não deixa arquivos permanentes; a memória declarativa é usada para declarar a existência e as características das coisas; e a memória procedural são hábitos que provém da aquisição de habilidades sensoriais e/ou motoras, não sendo fáceis de explicar de maneira declarativa. 
Com base no entendimento desses aspectos, compreendemos como é formada cognitivamente a memória individual. A partir disso, discutimos a produção de falsas impressões a respeito dos acontecimentos, responsável pela formação de falsas memórias, sendo esse o assunto abordado pelo texto dos pesquisadores em Psicologia Lilian Stein e Giovanni Pergher (2001). As falsas memórias são consideradas informações falsas armazenadas na memória, mas que são recordadas como se tivessem sido verdadeiramente vivenciadas.

Os autores também explicam o que é a recordação, que não se trata de uma reconstrução fidedigna do passado, na medida em que se caracteriza como um processo representacional movido pela subjetividade dos sujeitos. A partir disso, discute-se com os alunos a inadequação do uso do termo "resgate da memória", uma vez que o ato de lembrar é sempre realizado sob um determinado viés, pois lembramos apenas de fragmentos do ocorrido e não o reconstituímos em sua integridade. Sendo assim, não é possível resgatar a memória, pois ela não é lembrada da forma exata como os fenômenos transcorreram.

Após esses pressupostos sobre memória individual, os alunos são introduzidos em uma discussão sobre memórias coletivas, partindo dos estudos do filósofo e sociólogo Maurice Halbwachs (2013), que se debruçou sobre o estudo do nível de vida dos operários e a memória coletiva compartilhada por eles. Para ele, conforme nos socializamos, formamos memórias coletivas que asseguram nossos modos de vida, mas não impedem nossas mudanças face aos contextos econômicos e sociais. As memórias coletivas, para ele, dizem respeito às lembranças dos eventos e experiências vividos pela maioria dos membros do grupo, mas sempre dependem das memórias individuais, pois são os indivíduos que lembram, sendo cada memória individual apenas um ponto de vista sobre a memória coletiva. Nesse contexto, os testemunhos modificam o que já sabemos sobre um evento através das informações (HALBWACHS, 2013), atestando inclusive o fenômeno das falas memórias. Para o autor, nunca estamos sós, pois em pensamento sempre nos situamos em um específico grupo social, o que Halbwachs (1976) nomeia "quadros sociais da memória”, noção defendida também pelo autor anos antes e que se torna base para a obra póstuma "A Memória Coletiva” (2013).

Problematizando o conceito de memória coletiva, através da discussão sobre as "retóricas holistas", o professor de Antropologia da Universidade de Nice Antipolis e diretor do Laboratório de Antropologia e Sociologia "Memória, Identidade e Cognição Social", Joel 
Candau (2005) nos apresenta a noção de sociotransmissores, que encadeiam os três níveis taxonômicos da memória (protomemória, memória de alto nível e metamemória) e promovem a conexão entre as memórias dos indivíduos, potencializando a metamemória coletiva, a memória partilhada (OLIVEIRA, 2017). O autor também reconhece o patrimônio cultural enquanto dimensão política da memória e aborda questões como o mito e seu papel regulador da memória, os portadores de memória, atos de memória, as confusões no trabalho com memórias coletivas, dentre outros aspectos. Além disso, para Candau (2005), o esquecimento possui um caráter mais coletivo do que a própria recordação, pois há poucos elementos que são lembrados pelo coletivo, enquanto o que é esquecido é, em geral, esquecido pela maioria - ou seja, temos mais em comum aquilo que esquecemos do que aquilo que lembramos.

Professora titular do Programa de Pós-graduação em Memória Social da UNIRIO, Josaida Gondar é bacharel, mestre, doutora e pós-doutora em Psicologia, desenvolvendo pesquisas especialmente sobre sintomas contemporâneos, trauma, memória e criação, poder e cultura. É ela a escolhida para abordar alguns pressupostos teóricos a respeito do conceito de memória social. Gondar (2008) nos apresenta as diferenças possíveis entre memória coletiva e memória social, a partir da perspectiva de diversos autores. $\mathrm{Na}$ disciplina, tomamos a perspectiva de que memória coletiva diz respeito à memória compartilhada pelos povos sem domínio da escrita e que, assim, não possuem condições de registrar suas histórias. Já a memória social, nessa perspectiva, estaria mais relacionada aos povos que dominam a escrita, de modo que, registrando sua história, possuem o poder de perpetuá-la. Para Gondar (2016), a memória precisa ser pensada como relação, pois a partir de novas situações e novos encontros o passado é tanto recordado como reinventado.

Discutindo a complexidade do conceito de memória social, Gondar (2016) compreende que é impossível formar um conceito clássico, simples e unívoco. Entretanto, é possível traçar algumas proposições acerca do campo de estudo em memória social, tratando-o enquanto um campo transdisciplinar: seu conceito é ético e político; a memória implica o esquecimento; a memória não se reduz à identidade; a memória não se reduz à representação. A memória social é assim entendida como fruto do afeto, jamais estática, pois é moldada pelo que nos afeta e pelo novo. Portanto, não há memória sem criação e imaginação.

No ponto de vista desenvolvido em Santos (2003), a memória é problematizada conjuntamente com a História, estabelecendo a consciência de historicidade. Sujeitos dessa 
historicidade, os atores do presente podem utilizar-se da memória coletiva como representações sociais que trazem com ela uma dimensão histórica. A preocupação com a lente historiográfica para o desenvolvimento das competências e habilidades junto aos discentes na conceituação da memória social na perspectiva da História levou à utilização do texto clássico do filósofo francês Paul Ricoeur.

A lente historiográfica de Ricoeur (2007) em sua obra "A memória, a história, o esquecimento" contribuiu com o capítulo que trata da memória pessoal e coletiva. O autor aponta o acercamento do campo historiográfico nos estudos mnemônicos a partir da década de 1960, quando a ideia de desaparecimento e esquecimento foi trazida à tona na historiografia. A aproximação dos conceitos no campo historiográfico na disciplina Informação e Memória Social, com o texto de Ricoeur (2007), visou atentar para a percepção da presença do testemunho e do discurso narrativo. Para ele, a história só existe enquanto narrativa, e essas são expressas de diversas maneiras e em diferentes níveis onde há uma pluralidade de manifestação de diferentes vozes.

A leitura do texto de Ricoeur (2007) sobre a compatibilidade da história e da memória fez perceber seus vínculos com as noções de verdade e de justiça. Da falta de neutralidade das disputas narrativas e das ressignificações mediadas nas representações. Discutir conceitos como memória e história, que lidam com o passado, foi um desafio no sentido de confrontar atenção especial de que a História é uma forma elaborada de memória que vai além da vida individual, pois ela se manifesta no presente pelas experiências sociais individuais e coletivas, a partir das permanências e mudanças, conduzindo ao entendimento da mudança temporal.

Sob este prisma, desenvolveu-se a relação dos testemunhos e das construções narrativas a partir da História Oral, agregando a significação de tradição oral. A tradição oral, na caracterização da memória social, pressupõe identidade como forma de não esquecer a reprodução e a continuidade dos grupos. Ela incorpora pedaços da narrativa histórica e das mudanças do tempo. Segundo Ricoeur (2007), o relato de memória de uma testemunha é sempre a sua verdade. Tais definiçõos foram fundamentais para que os discentes desenvolvessem seu projeto final de conclusão e avaliação da disciplina: a construção de um memorial sobre si mesmos.

Os autores por nós reconhecidos como clássicos nos estudos da memória foram trabalhados em uma dinâmica de grupo, no formato seminário. Pierre Nora (1993), em seu 
texto "Entre memória e história: a problemática dos lugares" é discutido através do conceito de "lugar de memória", lugares com efeito nos três sentidos da palavra, material, simbólico e funcional, restos que partem de uma vontade de memória, resultado da aceleração da história. Já Aleida Assmann (2011) é fonte para o estudo acerca da memória situada nos locais. Segundo a autora, "a imediação onde eu moro" e "o espaço da casa do quintal do meu avô" refletem para nós uma memória da qual fizemos parte, mas que vai além de nós. Ecléa Bosi (1994) foi estudada por meio da obra "Memória e sociedade: lembranças de velhos". Bosi faz uso de outros quatro nomes do estudo da memória (Bergson, Halbwachs, Bartlett e Ster) para embasar seus estudos e análise da memória de idosos. Para Jacques Le Goff (1990), todo documento é um monumento, uma vez que todo documento deve ser pensado como construção, resultado de uma montagem consciente ou inconsciente da história, da época e da sociedade que o produziram, não uma verdade absoluta. Por fim, Michel Pollak (1989) serviu de referência para a discussão dos esquecimentos e silêncios que fazem parte da construção das memórias oficiais.

Tratou-se a respeito da História Oral, com a obra consagrada do tema pelas historiadoras Janaína Amado e Marieta Ferreira (1996). De acordo com as autoras, a História oral é um método de pesquisa nas ciências humanas que privilegia a realização de entrevistas com pessoas que testemunharam ou participaram de acontecimentos, conjunturas e visões de mundo.

O testemunho oral esclarece histórias individuais, eventos e processos não elucidados nas outras formas de documentação como caminho alternativo de interpretação, gerando documentos dialógicos intergeracionais e interpessoais. Como método, a História Oral via testemunho suscita recordações traumáticas, de forma que o entrevistador deve respeitar as suscetibilidades do entrevistado. Portanto, levanta a dimensão política da memória quando permite a exploração de questionamentos de mitos públicos, o que vale lembrar, é condição fundamental na formação e atuação de profissionais da CI.

A oralidade possui um importante papel na constituição da memória social, sendo também refletida pelo crítico literário, filósofo e sociólogo alemão Walter Benjamin. O autor, em seu clássico texto “O Narrador" (BENJAMIN, 1985), apresenta uma visão nostálgica a respeito do ato de narrar, vislumbrando um desaparecimento da figura do narrador e o consequente empobrecimento das narrativas de seu tempo. Contrapondo-se ao ritmo acelerado das sociedades industrializadas e ao automatismo, o autor apresenta uma visão idealizada sobre 
o passado, período no qual efetivamente eram contadas as "verdadeiras narrativas", advindas do discurso vivo da tradição oral, narradas pelos autênticos narradores, tais como os marinheiros comerciantes e os camponeses sedentários. Embora em um contexto específico, relacionado à escrita do romance e à imprensa, o autor critica a informação, que seria responsável pela morte da narrativa, devido ao seu caráter efêmero.

As interações através de ambientes virtuais possibilitam a manifestação de novas formas de memória, sempre moldadas pelos incessantes fluxos informacionais desses espaços. Esse contexto nos apresenta a uma problemática contemporânea: a virtualização da memória. A partir daí, surgem questões em torno de conceitos como memórias virtuais, memórias digitais, memórias em rede, memórias no ciberespaço e patrimônios digitais. Essa temática foi discutida em sala de aula a partir de diversos autores, dos quais destacamos: Vera Dodebei $(2006 ; 2011)$, Federico Casalegno (2006), Magda Cunha (2011) e Patrícia Mangan (2010).

Apresentamos até aqui os autores e as autoras que utilizamos para tecer os principais conceitos abordados na disciplina Informação e Memória Social. A seção a seguir relata as experiências de ensino e aprendizagem que vivenciamos ao longo do semestre 2017/2.

\section{INFORMAÇÃO E MEMÓRIA SOCIAL: EXPERIÊNCIAS DE APRENDIZAGEM}

A disciplina Informação e Memória Social foi criada em 2005 pelo DCI da UFRGS, sendo oferecidas semestralmente turmas com vagas para os cursos de Museologia (obrigatória do $2^{\mathrm{o}}$ semestre), Arquivologia, Biblioteconomia, Jornalismo, Publicidade e Propaganda, Relações Públicas e História da Arte (eletiva). Com carga horária de 60 horas (4 créditos), a disciplina possui um caráter teórico, visando apresentar aos estudantes do campo da CI e áreas correlatas, os principais autores, conceitos e abordagens dos estudos da memória, com especial destaque para a perspectiva da CI, com pequenas aproximações com as Ciências Humanas e Sociais (em especial as áreas da História, Sociologia, Antropologia e Comunicação).

Entendemos que os estudantes desses cursos precisam dominar esse conteúdo, uma vez que suas profissões estão diretamente relacionadas a questões políticas, educacionais, sociais e culturais da memória e da informação, sendo, por vezes, identificados como "guardiões da memória" e "gestores da informação". Dessa forma, alicerçada nesse conteúdo programático, a disciplina se propõe a refletir sobre os aspectos fundamentais relacionados à 
manutenção e/ou o questionamento das memórias socialmente partilhadas, dos esquecimentos compulsórios e institucionalizados e das memórias subterrâneas. Bibliotecas, arquivos e museus, em especial, são espaços de legitimação de narrativas históricas, espaços de poder e da dita "memória oficial", mas também devem ser lidos enquanto lugares de contestação que conformam essa mesma memória. São compreendidos, portanto, como lugares de memória (ou seriam de esquecimento?) por excelência. Tendo isso em vista, a disciplina apresenta inicialmente os seguintes objetivos:

a) Estudar as principais relações entre a história e a memória;

b) Estudar as relações entre a memória neurofisiológica e a memória social;

c) Conhecer as técnicas de pesquisa em História Oral;

d) Reconhecer os diversos suportes em que a memória social está registrada: fotografias, música, cinema em diversos suportes: a memória magnética e digital, a memória materializada na arquitetura e em monumentos.

A partir de nossa experiência didática na disciplina, transcorrida ao longo do semestre 2017/2, apresentamos um relato do seu desenvolvimento, refletindo sobre as melhores formas de abordar os estudos de memória social no campo da CI. No que tange à metodologia, a exposição oral e dialogada dos textos e autores é predominante no início da disciplina, especialmente para situar os discentes acerca dos conceitos estudados. Assim, são ministradas aulas introdutórias sobre memória neurofisiológica e falsas memórias, memória coletiva e memória social, tendo em vista o quadro teórico exposto na seção anterior. Nessas aulas, indicamos a leitura de um texto obrigatório e um texto complementar, além da exposição de filmes, documentários, letras de músicas e outros recursos didáticos auxiliares que evidenciassem questões relacionadas aos temas de cada aula.

Em função da disciplina fazer parte das etapas iniciais dos cursos, o que inclui geralmente alunos de $2^{\circ}$ semestre e, ainda, embasada em práticas pedagógicas atualizadas à geração digital, utilizaram-se recursos multimídia em sala de aula, tais como notebooks, tablets e celulares dos próprios alunos, a fim de que eles utilizassem aplicativos e mídias sociais (os quais já estavam acostumados), só que a partir de uma perspectiva acadêmica (pesquisa em sites institucionais, repositórios digitais e museus virtuais, por exemplo). 
A criação de um grupo da rede social Facebook, em uma das turmas, facilitou o diálogo entre os estudantes e potencializou a pesquisa através de postagens e compartilhamentos de materiais complementares. O Youtube foi utilizado para a exibição dos vídeos dos canais "Nostalgia" e "Minutos Psíquicos", com os temas: "Memória"2, "O palácio da memória e memória fotográfica" 3 "O computador ou o cérebro, quem é o mais potente?"4 e "A sua memória é boa?"5. Os documentários assistidos foram: "O cérebro humano. Emoções e Memória" do canal History Channel e "Alive Inside"6, disponível no serviço de streaming Netflix.

Foi ministrada às três turmas uma palestra sobre as memórias virtuais da cidade de Porto Alegre a partir das informações compartilhadas pelos usuários do aplicativo Foursquare . $^{7}$ Nessa oportunidade, além do relato de pesquisa do palestrante, também propomos aos estudantes que realizassem uma pesquisa rápida no aplicativo, buscando um lugar que fosse de seu interesse e identificando o que era narrado sobre esse lugar no aplicativo. Assim, eles puderam perceber na prática como são formadas memórias no aplicativo.

Tais métodos objetivaram aproximar as discussões teóricas e metodológicas próprias da disciplina com as necessidades e anseios da chamada Geração C, caracterizada por Figueroa (2017) como indivíduos criativos, com hábitos balizados pela internet, interligados por diversas plataformas, colaborando em comunidades, comentando, curtindo, customizando, criando e buscando diferentes experiências.

Após as aulas introdutórias, foram convidados palestrantes com experiência de pesquisa em informação e memória social para que relatassem seus estudos e pesquisas. Essas palestras foram oportunas para que os estudantes tivessem noção de modelos de pesquisa e metodologias, uma vez que as palestras incluíram temas como: direito à memória, memória

\footnotetext{
${ }^{2}$ NOSTALGIA. Memória. Youtube, 19 jun. 2014. Disponível em: < https://youtu.be/Bj-7axay48w> Acesso em: 16 mar. 2018.

3 NOSTALGIA. O palácio da memória e memória fotográfica. Youtube, 13 abr. 2017. Disponível em:

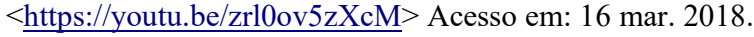

4 NOSTALGIA. O computador ou o cérebro, quem é o mais potente. Youtube, 9 jun. 2016. Disponível em: $<$ https://youtu.be/F6XGm0W0xQc > Acesso em: 16 mar. 2018.

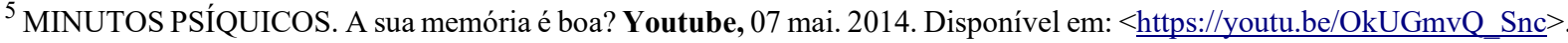
Acesso em: 16 mar. 2018.

${ }^{6}$ Considerado o documentário do ano de 2014, “Alive Inside”, dirigido por Michael Rossato-Bennett, relata a trajetória de Dan Cohen, fundador da organização sem fins lucrativos "Música e Memória" que objetiva demonstrar a capacidade da música de combater a perda de memória e restaurar vínculos emocionais mesmo para aqueles que sofrem com o esquecimento.

${ }^{7}$ O Foursquare é um aplicativo que utiliza localização inteligente para criar experiências de consumo e lazer com a cidade. Nele, as informações compartilhadas são contribuições dos usuários, que publicam "dicas" sobre os lugares, caracterizando-o como uma rede social virtual gratuita.
} 
institucional, cidade e memória e memória e nostalgia. Ainda acerca de pesquisas em memória social, também foi ministrada uma aula sobre história oral, que é um dos principais métodos de pesquisa utilizados nesse campo de estudos.

Nesse momento, fez-se uso dos escritos de Janaina Amado e Marieta Ferreira (1996), Paul Thompson (2002) e Norberto Luiz Guarinello (1998). Também foi ministrada uma aula sobre a perspectiva singular de Walter Benjamin (1985) a respeito das narrativas e da narração, de modo a problematizar o que se pode entender como narrativa e quem pode ser considerado narrador. Como estratégia motivacional na condução da discussão dos conceitos apresentados, utilizou-se como recurso didático, na Turma C, o filme "Uma cidade sem passado" (UMA CIDADE..., 1990) ${ }^{8}$, atividade que teve caráter reflexivo e avaliativo.

As atividades avaliativas incluíram a participação em seminários em grupo, a elaboração de um mapa conceitual sobre os conceitos e noções trabalhados na disciplina (em uma das turmas), a reflexão a respeito de um conto específico e a elaboração de um memorial, através do qual os estudantes contavam histórias pessoais de suas vidas, colocando-se no papel de narradores. Os seminários foram estruturados a partir da escolha de cinco textos que deveriam ser lidos pela turma, cada texto por um grupo que deveria apresenta-lo em um tempo estipulado de aproximadamente 20-30 minutos, apresentando o autor, os conceitos abordados, as teses e os argumentos defendidos por ele. Sugeriu-se que os alunos não elaborassem apresentações em Power Point, para que cada um permanecesse sentado em seu lugar, com a turma formando um círculo. Essa metodologia se mostrou bastante adequada, pois os estudantes relataram sentir-se mais à vontade ao poderem falar de seus próprios lugares.

No primeiro seminário, foram abordados textos de autores referenciais no campo da memória, quais sejam: Pierre Nora (1993), Ecléa Bosi (1994), Aleida Assmann (2011), Jacques Le Goff (2003) e Michael Pollak (1989). Nesse momento, discutiram-se questões como memória e esquecimento, lugares de memória, espaços de memória, corpo e memória e os conceitos de documento e monumento. No segundo seminário (aplicado apenas na Turma $\mathrm{B}$, em função de adequações na execução do cronograma), a temática foi a virtualização da memória, incluindo questões como memória no ciberespaço, memória digital, memória virtual, memória em rede, patrimônio digital, etc. Para tanto, a turma foi dividida novamente em cinco

\footnotetext{
${ }^{8}$ O filme "Uma cidade sem passado" (1990) é da Alemanha, dirigido por Michael Verhoeven e trata sobre questões como os usos sociais e políticos da memória, história, verdade, testemunhos, História Oral e trauma. Os alunos e alunas puderam assisti-lo em casa e foi realizado um debate acalorado sobre a obra, além da escrita de um ensaio.
} 
grupos que leram textos de Vera Dodebei (2006), Magda Cunha (2011), Federico Casalegno (2006), Patrícia Mangan (2010) e Fabiana Lazzarin, Carlos Xavier Netto e Marckson Souza (2015). No caso das turmas A e C, que não puderam realizar o Seminário, uma aula aberta sobre o tema foi realizada, como parte dos "relatos de pesquisa em memória social" e com a participação de um palestrante.

Realizou-se também uma atividade à distância em que os estudantes refletiram sobre o conto "Funes, o Memorioso", de Jorge Luis Borges (1969). No conto, Funes possui a capacidade de nunca se esquecer de nada, o que lhe causa certos inconvenientes e desconfortos. Solicitamos aos alunos que, a partir das questões debatidas em aulas, refletissem sobre o conto, evidenciando de que modo questões teóricas sobre memória individual, coletiva e social são abordadas na obra.

A atividade que encerrou a disciplina foi a apresentação dos memoriais elaborados pelos estudantes. Para tal, destinaram-se os últimos dois encontros da disciplina, nos quais cada aluno teve o tempo de até 10 minutos para apresentar um memorial sobre sua vida ou sobre algum evento que desejasse compartilhar com os colegas, assumindo o papel de narrador da história. Permitimos que se usasse quaisquer tipos de materiais e os alunos elaboraram apresentações em power point, vídeos, músicas, fotografias, bandeiras e outros objetos. Foi um momento marcante, pois os alunos riram das histórias engraçadas contadas por alguns colegas, mas também ocorreram momentos de emoção e empatia a partir das narrativas com os relatos tristes sobre os entes queridos que já faleceram, as histórias de superação de vida, as dificuldades e demais fenômenos que o estudo da memória individual nos permite abordar.

Alguns alunos, no início da disciplina, demonstraram certa resistência à ideia de elaborar um memorial, seja pela timidez em compartilhar uma história pessoal com o grande grupo ou por não perceberem a relevância dessa atividade para uma disciplina acadêmica. Entretanto, ao final do curso, muitos revelaram que gostaram da atividade, tanto de preparar o memorial, como de apresenta-lo e assistir aos memoriais dos colegas. Muitos relatos de alunos afirmaram o quanto essa atividade funcionou e serviu de revisão de todo conteúdo estudado, mas também, como uma espécie de terapia pessoal, já que puderam, de fato, não só compreender o conteúdo ministrado no decorrer do semestre, mas associá-lo a outras disciplinas e a sua própria vida, na prática. 
Foi uma forma criativa e divertida de conhecer um pouco melhor uns aos outros, especialmente pela disciplina ser eletiva para boa parte dos alunos. Como atividade de avaliação, ainda que não tenha sido demandado, muitos alunos buscaram citações teóricas examinadas nos textos e as incluíram nos próprios memoriais, o que foi um feedback excelente que permitiu aos professores perceber os destaques que se fixaram na memória seletiva dos estudantes.

\section{CONSIDERAÇÕES FINAIS}

O DCI se situa em um espaço privilegiado para proporcionar uma discussão transversal que unifica, mas, ao mesmo tempo, singulariza as áreas da Arquivologia, da Biblioteconomia e da Museologia. Na disciplina Informação e Memória Social, esse espaço de debate toma novo fôlego, uma vez que somados aos cursos de CI os cursos de Comunicação e História da Arte contribuem ativamente.

Devido ao seu destaque enquanto ciência dedicada à análise crítica dos fenômenos informacionais, o que inclui todos os processos que permitem a disseminação das informações para a sociedade, a CI demanda das discussões próprias do campo da memória social, uma vez que dela dependem a gestão e manutenção das memórias cristalizadas em suportes materiais.

O conteúdo programático abarcou os estudos biológicos, psicológicos, filosóficos, históricos e sociológicos da memória, seja na sua dimensão individual, do afeto e da sensibilidade; ou na dimensão coletiva, das representações sociais. Dessa maneira, fica evidente que o campo de estudo em memória social tem muito a contribuir para a formação dos cursos nos quais a disciplina é ofertada, ainda mais quando se reflete sobre o contexto político atual, onde esquecimentos e silêncios forçados constroem a memória oficial e marginalizam tantas outras, seja pelo seu apagamento ou pelo desprezo a práticas, saberes e narrativas de grupos sociais distintos.

As atividades pedagógicas e avaliativas executadas objetivaram a aplicação de uma dinâmica de pesquisa e aprendizagem por processo, sempre associando teoria e prática, pesquisa acadêmica e exercício de cidadania. $\mathrm{O}$ uso de processos e ferramentas da era digital 
gerou interesse e engajamento por parte dos alunos e culminou em trabalhos finais com densidade teórica e autorreflexão.

O propósito e a responsabilidade dos estudos sobre memórias individuais e sociais nos cursos de graduação do campo da CI está na mescla da reprodução e da mudança nas relações que seus futuros profissionais e atuais cidadãos terão nas disputas e seleções dessas memórias produzidas em espaços de arquivos, bibliotecas, museus e na mediação e disseminação da informação. Ao utilizarmos de diferentes referenciais teóricos, mostramos a relatividade do conhecimento científico, e que o saber é estratégico, mas também plural e engajado em estabelecer relações a partir das articulações e compartilhamentos dessas teorias com as experiências vivenciadas.

Certamente, a memória e a história de alunos e alunas que têm a possibilidade de atingir a universidade pública, gratuita e de qualidade será constituída de formação que permitirá a eles e elas a capacidade de compreender e explicar fenômenos sociais do contexto em que se inserem, podendo ou não modificar e transgredir suas práticas sociais e pessoais sendo, portanto, sujeitos e agentes históricos. 


\section{REFERÊNCIAS}

AMADO, Janaína; FERREIRA, Marieta. Usos e abusos da história oral. Rio de Janeiro: FGV, 1996.

ASSMANN, Aleida. Espaços da recordação: formas e transformações da memória cultural. São Paulo: Editora da Unicamp, 2011.

BENJAMIN, Walter. O narrador: considerações sobre a obra de Nikolai Leskov. In: BENJAMIN, Walter. Magia e técnica, arte e política. São Paulo: Brasiliense, 1985. p. 197221.

BORGES, Jorge Luis. Funes, o memorioso. In: BORGES, Jorge Luis. Ficções. Porto Alegre: Globo, 1969.

BOSI, Ecléa. Os espaços da memória. In: BOSI, Ecléa. Memória e sociedade: lembranças de velhos. 3. ed. São Paulo: Companhia das Letras, 1994. p. 434-452.

CANDAU, Joel. Antropologia da memória. Lisboa: Instituto Piaget, 2005. p. 66-97.

CASALEGNO, Federico. Federico Casalegno: uma abordagem ecológica da memória em rede. In: CASALEGNO, Federico. Memória cotidiana: comunidades e comunicação na era das redes. Porto Alegre: Sulina, 2006. p. 19-33.

CUNHA, Magda Rodrigues da. Memória na era da reconexão e do esquecimento. Em Questão, Porto Alegre, v. 17, p. 103-117, 2011.

DODEBEI, Vera Doyle. Memória e patrimônio: perspectivas de acumulação/dissolução no ciberespaço. Revista Aurora, São Paulo, n. 10, 2011.

DODEBEI, Vera. Patrimônio e memória digital. Morpheus, Rio de Janeiro, v. 4, n. 8, 2006.

FIGUEROA, Franz. Processos criativos para a educação na era digital. Palestra ministrada aos alunos do $2^{\circ}$ Fórum $\mathrm{EaD}$ da UFRGS, 2017. Disponível em: $<$ http://www.ufrgs.br/sead/news/processos-criativos-para-educacao-na-era-digital-foi-o-temado-2o-forum-ead-ufrgs-2017>. Acesso em: 19 dez. 2017.

GONDAR, Jô. Cinco proposições sobre memória social. Morpheus, Rio de Janeiro, v. 9, n. 15, p. 19-40, 2016.

GONDAR, Jô. Memória individual, memória coletiva, memória social. Morpheus, Rio de Janeiro, v. 8, n. 13, 2008.

GUARINELLO, Norberto Luiz. Breve arqueologia da história oral. História Oral, v. 1, 1998, p. 61-65. 
HALBWACHS, Maurice. Los marcos sociales de la memoria. Caracas: Anthropos Editorial, 1976.

HALBWACHS, Maurice. Memória coletiva e memória individual. In: A memória coletiva. 2. ed. São Paulo: Centauro, 2013. p. 29-70.

IZQUIERDO, Iván. Questões sobre memória. São Leopoldo: Editora Unisinos, 2004. p. 1525 .

LAZZARIN, F. A.; AZEVEDO NETTO, C. X.; SOUZA, M. R. F. Informação, memória e ciberespaço: considerações preliminares no campo da Ciência da Informação no Brasil. Transinformação, Campinas, v. 27, p. 21-30, 2015.

LE GOFF, Jacques. Documento/monumento. In: LE GOFF, Jacques. História e memória. Campinas: Ed. da UNICAMP, 2003. p. 525-541.

MANGAN, Patrícia Kayser Vargas. Construção de memórias digitais virtuais no ciberespaço. In: FRANÇA, Cristina Caminho de Castilhos; LOPES, Cícero Galeno; BERND, Zilá (Org.). Patrimônios memoriais: identidades, práticas sociais e cibercultura. Porto Alegre: Movimento; Canoas: Unilasalle, 2010.

NORA, Pierre. Entre a memória e a história: a problemática dos lugares. Projeto História, São Paulo, v. 10, dez. 1993, p. 7-28.

OLIVEIRA, Priscila Chagas. Interfaces da memória social: análise do compartilhamento do conjunto de imagens digitais do Acervo Digital Bar Ocidente no Facebook. 2017. 146 f. Dissertação (Mestrado em Memória Social e Patrimônio Cultural) - Programa de PósGraduação em Memória Social e Patrimônio Cultural, Instituto de Ciências Humanas, Universidade Federal de Pelotas, Pelotas, 2017.

POLLAK, Michel. Memória, esquecimento, silêncio. Estudos Históricos, Rio de Janeiro, v. n. 3, p. 3-15, 1989.

RICOEUR, Paul. A memória, a história, o esquecimento. Campinas: Ed. da UNICAMP, 2007.

SANTOS, Myriam Sepúlveda. Memória coletiva \& teoria social. São Paulo: Annablume, 2003.

STEIN, Lilian Milnitsky; PERGHER, Giovanni Kuckartz. Criando falsas memórias em adultos por meio de palavras associadas. Psicologia: reflexão e crítica, v. 14, n. 2, p. 353-366, 2001.

THOMPSON, Paul. História oral e contemporaneidade. História Oral, n. 5, p. 9-28, 2002.

UMA CIDADE sem passado. Direção: Michael Verhoeven. [S.1.], 1990, 1 DVD. 92 min. 